\title{
Un viaje a Newark en busca de la polio
}

\section{A trip to Newark in search of polio}

\section{Uma viagem de Newark em busca de pólio}

Artículo basado en la Ponencia al III Simposio Iberoamericano de Historia de la Enfermería, XII Congreso Nacional VII Internacional de Historia de la Enfermería y VII Jornadas Internacionales de Cultura de los Cuidados

Francisco Herrera Rodríguez

Facultad de Enfermería y Fisioterapia (Universidad de Cádiz)

A Juan Valentín Fernández de la Gala, amigo y cómplice literario.

“PPor qué pilló Allan la polio? ¿Por qué ha tenido que enfermar y morir?”

Philip Roth, Némesis.

"Sigo siendo el amorfo Roth".

Philip Roth (2008).

\section{ABSTRACT}

In this paper we present a study on Philip Roth's latest novel, Nemesis, in which the American writer reflects on the epidemic of polio in Newark (1944)

Key words: Philip Roth; Literature; epidemic, poliomyelitis, Nemesis.

\section{RESUMO}

Neste artigo apresentamos um estudo sobre o último romance de Philip Roth, Nemesis, em que o escritor norte-americano reflete sobre a epidemia de poliomielite em Newark (1944).

Palavras-chave: Philip Roth; Literatura; epidemia, poliomielite, Nemesis.

\section{RESUMEN}

En este artículo presentamos un estudio sobre la última novela de Philip Roth, Néme- sis, en la cual el escritor norteamericano reflexiona sobre la epidemia de poliomielitis en Newark (1944).

Palabras clave: Philip Roth; Literatura; Epidemias; poliomielitis, Némesis.

"Némesis" es la última novela publicada por Philip Roth, el gran escritor norteamericano para el que el célebre crítico Harold Bloom reclama una y otra vez el Premio Nobel de Literatura. Roth es un escritor muy laureado y, lo que es más importante, leído y valorado, tanto en América como en Europa; todo ello al margen de sus peculiaridades neuróticas que según las lenguas de doble filo han sido reflejadas descarnadamente por Woody Allen en "Desmontando a Harry", una magnífica comedia, ácida y felliniana, a la que hay que cogerle el punto para disfrutarla. Alguien ha dicho que Roth y Allen son como dos hermanos gemelos a los que separaron al nacer y es que hay muchos temas comunes en sus respectivas obras (familia, infancia, amor, desamor, sexo y una presencia capital de lo judío), y probablemente más de una espina clavada y mutuas afrentas, pero dejemos este asunto a la prensa sensacionalista norteamericana o mejor a la gente que estudia todas estas cuestiones con seriedad (figura 1). 


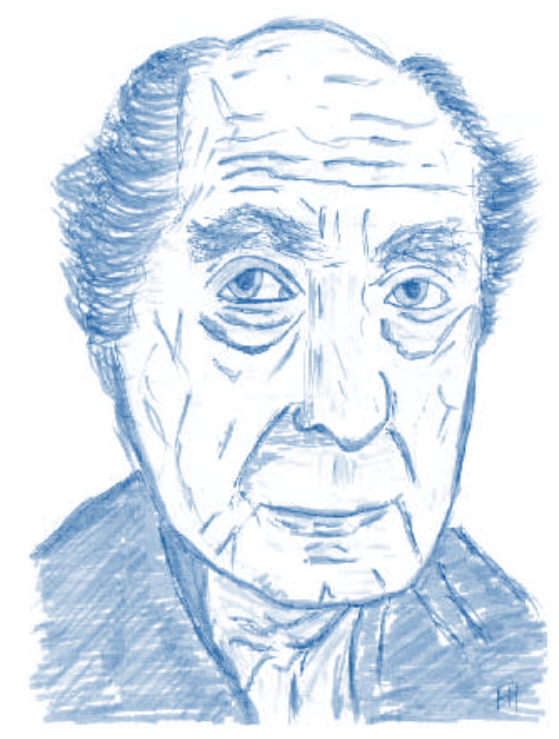

Figura 1: Caricatura de Philip Roth. Rotulador (FHR, 2011).

Philip Roth nació en 1933 en Newark, ciudad del condado de Essex en el estado de Nueva Jersey; observamos en el conjunto de su obra, además de los temas apuntados, una gran preocupación por la salud y la enfermedad; recuerdo ahora a ese androcéntrico personaje de "El pecho", David Kepesh, que aparece de pronto convertido en una glándula mamaria de más de 70 kilogramos de peso, imagen que por cierto también aparece en la filmografía de Woody Allen; en esta novela el protagonista demanda constantemente gratificaciones eróticas, pero a partir de un momento duda sobre su equilibrio mental y pregunta si se ha vuelto loco o realmente le está pasando lo que le está pasando. Todo muy kafkiano y con netas resonancias de "La metamorfosis". No se olvide que Kafka es uno de los referentes literarios de Philip Roth. En "El animal moribundo", una de sus novelas más criticadas, también hay alusiones kafkianas y aparecen las enfermedades nuevamente, por ejemplo: la apoplejía y muerte de George O’Hearn y el cáncer de mama que padece la protagonista, Consuelo Castillo, una antigua alumna y amante de un profesor, picaflor e insaciable, que encuentra su mejor alimento erótico en las jóvenes que quedan fascinadas por el verbo y la erudición que despliega en las aulas. La apoplejía y el cáncer de próstata están presentes en otra de sus novelas, "Elegía", que no entusiasmó a algunos críticos; sin olvidarnos de uno de sus libros más logrado "Patrimonio. Una historia verdadera”, en el cual narra magistral y entrañablemente la reacción de su propio padre, Herman Roth, cuando ya octogenario le diagnostican un tumor cerebral; hecho que provoca un auténtico cataclismo en sus vidas, a la vez que le permite a Roth rendir tributo a la tenacidad y capacidad de lucha de su progenitor, de quien ya había escrito en "Los hechos": "Su sabiduría consiste en relatar, y su repertorio nunca ha sido muy amplio: familia, familia, familia, Newark, Newark, Newark, judío, judío, judío. Como yo, más o menos". José Manuel Guelbenzu, escritor y crítico literario, dijo de este libro que "es una deuda de amor y un acto de entendimiento". Efectivamente, eso es lo que encontramos en "Patrimonio": un intenso acercamiento paternofilial, no muy común en la literatura universal, en el que está presente la vida, la salud, la enfermedad y la muerte. La lectura de este libro nos lleva a corroborar la idea que recientemente ha publicado Vicente Verdú sobre la importancia de la comunicación entre las personas y muy particularmente cuando llega la enfermedad:

"Los seres humanos se han matado entre sí, pero entre ellos se halla la fuente de la curación a lo largo de los siglos. Los diferentes mitos en 
torno al religioso cuerpo místico tienen su traducción en la verdad (laica y dogmática) de que mediante la relación con los demás las penas se demedian y, al menos temporalmente, se amortizan".

Pero centrémonos ya en "Némesis", una novela escrita con lenguaje eficaz y directo, aunque con un desarrollo clásico que recuerda a aquello del planteamiento, el nudo y el desenlace, o bien a los tres actos de una obra de teatro, aunque al final encontramos una sorpresa en el desvelamiento de quién es realmente el narrador; un narrador que sitúa a esta novela muy cercana a los estudios de algunos antropólogos, historiadores, psicólogos sociales y sociólogos que cultivan fervorosamente las historias de vida. No cabe duda de que Philip Roth se ha documentado con una bibliografía muy selecta para construir este libro como es el caso de "Polio Voices" de Julie Silver y Daniel Wilson, entre otras; pero seguro que también ha tenido muy presente los recuerdos personales de esta epidemia de polio de 1944 cuando contaba tan sólo 11 años de edad; aunque somos consciente de que el escritor norteamericano ha desmentido alguna vez que su obra revista un carácter autobiográfico y que prefiere que sus libros se lean "como obras de ficción"; esto es perfectamente posible porque su obra amalgama la experiencia de lo vivido y la imaginación, resultando un estilo propio que le otorga a sus textos una dimensión artística. Si la obra de Roth interesa es precisamente porque habla de la vida y de lo vivido de una manera diferente, ya que como suelen decir los críticos literarios posee una "voz propia".

Volvamos a la novela. El desarrollo de la misma se lleva a cabo parcialmente en Newark (Nueva Jersey), ciudad natal y territorio mítico en la literatura de Roth/Zuckerman; como Comala lo es para Rulfo o Macondo para Gar- cía Márquez o Santa María para Onetti o la Argónida para Caballero Bonald; todos estos escritores, aunque no estoy seguro en el caso de Philip Roth, tienen una marcada huella de William Faulkner, recuérdese en ese sentido la influencia ejercida por "Santuario". Influenciado o no por Faulkner, Roth consigue transformar el Newark real en un Newark mítico, referente universal para todos los seres humanos. Eso en literatura sólo lo consiguen los grandes escritores.

¿Pero qué pasó en Newark en el verano de 1944? Una epidemia de poliomielitis aterrorizó a la población y mató a niños que aún tenían toda una vida por delante. Pero además no se olvide que en esos momentos los Estados Unidos participaban activamente en la II Guerra Mundial. Tiempos de guerras, tiempos de enfermedad. El planteamiento está servido para que aflore una historia dramática, o trágica como indica Guelbenzu, en la que surgen preguntas fundamentales sobre la vida, la muerte y la enfermedad. Una novela cuyo marco genérico es una asoladora epidemia; esto recuerda, por ejemplo, a "La peste" de Albert Camus, obra que Philip Roth leyó concienzudamente antes de redactar su "Némesis". Conviene, pues, ya que la acción de la novela está marcada por tiempos de guerra y de enfermedad, que acudamos a la Enciclopedia y aclaremos el significado de esta enigmática palabra, Némesis:

"Diosa de la venganza. Tenía santuarios. Es la personificación de una noción esencial del pensamiento helénico: la del equilibrio inmutable de la condición humana. Todo hombre que incurre en "desmesura" provoca la ira de los dioses o de sus celos, y se atrae la venganza personificada en Némesis, representación mitológica de la justicia y suerte personal del ritmo del destino, que a menudo hace que los excesos 
de prosperidad o de orgullo vayan seguidos de grandes desgracias".

Al leer este texto uno se pregunta inmediatamente: ¿esta venganza se ceba en el personaje central de la novela, Bucky Cantor?, un joven entusiasta que por problemas en la vista no puede ir a la guerra como sus amigos, ¿o bien sobre la sociedad norteamericana en su conjunto? Y la respuesta es que nadie se libra y mucho menos el "señor Cantor". No se olvide que son años “... en que parecía que las mayores amenazas en la tierra eran la guerra, la bomba atómica y la polio". Al final se pagó un precio muy caro, individual y colectivamente. Según avanzamos en la narración observamos que hay un cierto planteamiento levítico: la ruptura del "equilibrio inmutable" de la condición humana, como consecuencia de una atroz guerra, tiene su castigo con una enfermedad que fustiga a buena parte de la población y sobre todo a niños inocentes llenos de fuerza y de entusiasmo. El joven protagonista Bucky Cantor, gran deportista e instructor deportivo, se pregunta sobre el papel de Dios, justo en el momento en que bajan a la tumba el ataúd de un alumno suyo y el rabino recita una plegaria, pregunta que en cierta medida recuerda el discurso radical de Mark Twain en "Reflexiones contra la religión":

"Sin duda, tampoco él (Bucky Cantor) se hubiera atrevido a volverse contra Dios por arrebatarle a su abuelo cuando el anciano alcanzó una edad adecuada para morir. Pero ¿y por matar a Allan con la polio a los doce años? ¿Por la misma existencia de la polio? ¿Cómo podía haber perdón -y no digamos aleluyas- ante una crueldad tan demencial?".

En otro momento de la novela, pero siguiendo la misma línea de pensamiento, el protagonista se plantea radicalmente lo siguiente: “Y qué pinta Dios en todo esto? (...)
¿Por qué sitúa a un niño de Weequahic en la Newark infestada de polio durante el verano $y$ a otros en la espléndida reserva natural de las montañas Pocono? O bien estas otras: “Por qué no atendió Dios las plegarias de los padres de Allan Michaels? Deben haber rezado, lo mismo que los padres de Herbie Steimar. Son buena gente, son buenos judios. ¿Por qué Dios no hizo nada por ellos? ¿Por qué no salvó Él a sus hijos?". Bucky Cantor se rebela humana e intelectualmente contra Dios por todo ello y trata de comprender estos interrogantes y sucesos amparándose en los argumentos de cierta filosofía existencialista, amparándose en la idea de la "tiranía de la contigencia"; es decir, en la idea de que estamos solos y desvalidos ante el azar.

Algunos chicos enferman en Newark; pero, en principio, 40 casos de polio en una ciudad con 429.000 habitantes, según las autoridades sanitarias, no es cifra suficiente para declarar la existencia de una epidemia. Sin embargo a los más viejos de la población, según se narra en la novela, les viene a la mente la epidemia de polio de 1916 "en el nordeste de Estados Unidos, cuando se habian dado más de 27.000 casos y 6.000 fallecimientos. En Newark habia habido 1.360 casos y 363 muertos".

En 1944, año en que se desarrolla la acción de la novela, aún no existía una vacuna efectiva contra la enfermedad, por lo que muchos niños estaban abocados a la parálisis de los músculos respiratorios, al pulmón de acero y, por supuesto, a la muerte. Ante este panorama, en la mente de los padres tampoco producía una especial tranquilidad que el famoso presidente Franklin Delano Roosevelt, enfermo también de polio, hubiera creado una institución benéfica, la "March of Dimes", que se encargaba de recoger dinero para la investigación y de la ayuda económica a las familias de los afectados. No nos sorprende en absoluto 
esta inquietud familiar y social, ya que la poliomielitis causó estragos en la década de los cuarenta y en la de los cincuenta. De hecho en los Estados Unidos el número anual de casos se multiplicó por cuatro a partir de 1930, llegando a alcanzar cifras del orden de 55.000 a 60.000 casos por año durante la primera mitad de la década de los 50. Algunos ejemplos numéricos nos permiten comprobarlo: en 1944 la tasa en Estados Unidos fue de 13,78 casos por 100.000 habitantes (gráfico 1), aunque en Dinamarca, Suiza y Suecia era peor con 48,02, 41,11 y 41,40, respectivamente. En España la morbilidad, en 1944, era muy inferior aproximándose a 2; sin embargo en la provincia de Cádiz en ese mismo año la situación era muy preocupante con 6,27 casos por 100.000 habitantes.

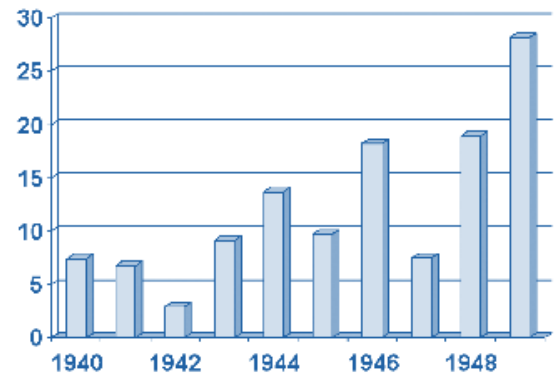

Gráfico 1: La poliomielitis en Estados Unidos (1940-1949) (Número de casos por 100.000 habitantes). Obsérvese la situación en 1944 (13,78), aunque en años posteriores de la década de los cuarenta la situación empeoró, sobre todo en 1946, 1948 y 1949. Elaboración propia (2011). Fuentes: Nájera E y col (1975) y León Rega P. y Echevarria Mayo JM.

No vamos a entrar en detalle pero en este "Newark ecuatorial", como es calificado en la novela, la enfermedad avanza y se cobra vidas; por ello la población empieza a buscar culpables, con argumentos más o menos racionales; nuevamente encontramos que en una situa- ción de catástrofe epidémica se buscan chivos expiatorios. El miedo provocó que en Newark la situación no fuera diferente y entre otras "etiologías" algunos miembros de la población señalaron como responsable a la leche de vacas sucias que beben los niños, a las botellas de la leche sin esterilizar, a un "retrasado" del barrio llamado Horace, a una brisa que llegó después de un calor sofocante, a los perritos calientes de un local de Syd, a las moscas, a las granjas porcinas de Seacaucus, a las asistentas de color que trabajaban en el barrio de Weequahic, a los italianos del instituto de East Side; en este último caso no olvidaban la visita hostil que hicieron estos italianos al colegio donde trabajaba el abnegado y voluntarioso Bucky Cantor. Leamos el pasaje porque no tiene desperdicio, tanto en lo etiológico como en el odio y resentimiento existente dentro de una misma población:

“¿¿Qué venís a hacer aquí? -les preguntó el señor Cantor.

-Estamos propagando la polio -respondió uno de los italianos (...).

-Más bien parece que estáis propagando problemas -le dijo el señor Cantor- ¿Por qué no os largáis de aquí? (...).

-No, no -insistió el chico italiano-, no hasta que hayamos propagado algo de polio. Nosotros la tenemos y vosotros no (...).

-Mira, la polio no es ninguna broma (...).

En aquel momento, el jefe de la jauría, que era por lo menos quince centímetros más alto que el señor Cantor, dio un paso adelante y escupió en el suelo. Dejó allí un viscoso gargajo, a unos pocos centímetros de las zapatillas del señor Cantor".

Todo un símbolo, a mediados de los años cuarenta, ese "gargajo" arrojado al suelo en este barrio de Newark, sobre todo si tenemos en cuenta lo que estaban padeciendo los judíos en 
Europa y más concretamente en Alemania; he aquí uno de los grandes hallazgos narrativos de Roth en la novela, relacionando de forma inexorable odio, racismo, guerra y enfermedad; de forma análoga a lo que hizo Albert Camus cuando correlaciona el nazismo con la peste. Vargas Llosa también ha señalado el sentido metafórico del "cólera hindú" en " $\mathrm{La}$ muerte en Venecia" de Thomas Mann.

Pero ahí no queda la cosa porque el propio Bucky Cantor es acusado por la señora Kopferman por hacer jugar a "softball" a los niños que están a su cargo:

“-¡Ustedi -le gritó la mujer-. ¿Tiene la desfachatez de llamar? (...).

-Le aseguro, señora Kopferman, que tengo cuidado con todos los chicos.

-¿Por qué entonces mis hijos están paralizados? iMis dos hijos $;$ iTodo lo que tengo ${ }_{i} E x-$ plíquemelo; Los deja correr como animales por ese patio...iy se extraña de que cojan la polio; ¡Por su culpa ${ }_{i}$ Debido a un idiota imprudente e irresponsable como usted; -Y la mujer colgó sin decir nada más".

Un médico le dice a Bucky Cantor algo así: tranquilo el softball no produce la polio, la produce un virus; "puede que no sepamos gran cosa de la polio, pero eso lo sabemos con certe$z a$ "; sin embargo, la señora Kopferman lanza la acusación porque seguro que en su entorno ha escuchado que algunos médicos relacionan la fatiga física con la polio. En la década de los cincuenta, por ejemplo, Barraquer y Sales afirman lo siguiente: "Cierto número de factores pueden favorecer la aparición de una forma paralítica de la poliomielitis. Entre los más importantes hay que citar la fatiga física; tanto clínica como experimentalmente se ha demostrado la importancia del factor fatiga en el periodo preparalítico". Además de todo esto unos opinan que habría que poner "brazaletes" identi- ficando a las familias en las que hay enfermos y otros que se cierren los centros. El miedo va ganando la partida, léase el siguiente diálogo entre Bucky Cantor y algunos de los niños que están a su cargo:

“-Sé que es duro para vosotros, muy duro. Debemos confiar en que mejorarán y en que pronto estarán de nuevo en el centro.

-Puedes acabar metido en un pulmón de acero para siempre -dijo Bobby Finkelstein, un chico tímido que era de los más silenciosos, uno de los tres niños que él había visto trajeado en los escalones de la sinagoga tras el funeral de Allan Michaels".

-Es cierto -replicó el señor Cantor-. Pero esos casos son de parálisis respiratoria, que es muy infrecuente. Es mucho más probable que te recuperes. Es una enfermedad grave, puede hacer mucho daño, pero también hay quien se recupera. A veces de forma parcial, pero en muchas ocasiones completamente. La mayoría de los casos son relativamente leves. -Hablaba con autoridad, y la fuente de su conocimiento era el doctor Steinberg".

Nadie entiende en Weequahic, el barrio judío de Newark, lo que pasa; los más racionales hablan de virus, pero lo que impera es el miedo como en la peste de Londres, narrada por Defoe, o en la peste de Orán de Albert Camus o en la ceguera de Saramago, y, en cierta forma, en el miedo latente que se percibe en algunos pasajes de "La Montaña mágica" de Thomas Mann. El miedo a la muerte, el miedo a la enfermedad y quizás también el miedo a la vida o a las incertidumbres de la vida que unos tratan de resolver con la cooperación activa, el recogimiento y la oración, la indiferencia o la inconsciencia, y otros quizás con la disipación, la mutilación y la violencia. En esta línea habría que repasar algunos de los carismáticos personajes de Dostoievski. 
Miedo, sí, pero también la culpa está muy presente en la novela, quizás sea el argumento central de la misma, sobre todo cuando se cuenta el estado anímico de Bucky Cantor muchos años después de esta epidemia de polio; para entenderlo hay que tener en cuenta que este hombre llevaba labrada en su conciencia la culpa a fuego: se siente culpable de que su madre hubiera muerto en el parto, de que su padre hubiera sido un ladrón, de haber sido portador de la polio, de haber transmitido la enfermedad a la que iba a ser su cuñada, de no haber ido a la guerra, de haber desertado del colegio cuando la epidemia se cebaba con sus alumnos, de haber soñado por un momento que iba a ser feliz. El señor Cantor, el hombre más responsable entre los hombres responsables, se siente culpable de todo y por todo, y muchos años después de la epidemia es una pálida sombra que deambula por las calles de la ciudad. Es la sombra de un superviviente que se siente culpable de todo cuando simplemente es una víctima más de las muchas que generó esa encrucijada histórica de los años cuarenta. Leamos:

"En general, le rodeaba un halo de fracaso indeleble mientras hablaba de todo lo que había silenciado durante años, de un hombre no solo físicamente lisiado por la polio sino también desmoralizado por una vergüenza perenne. Era la misma antítesis del mayor prototipo de víctima de la polio del país, Franklin Delano Roosevelt, (...). La parálisis y todas sus secuelas habian dañado irremediablemente la seguridad en sí mismo y su virilidad, y se había retirado por completo de esa faceta de la vida. Se consideraba asexuado, una especie de cartucho de fogueo, una valoración que no podía resultar más humillante para un muchacho que había alcanzado la mayoría de edad en una época de sufrimiento y conflictos para la población esta- dounidense, cuando los hombres debían ser impertérritos defensores del hogar y del país".

Philip Roth podía haber escrito un ensayo histórico, pero quizás apostó por lo más difícil construir una novela con un personaje prodigioso, Bucky Cantor, que en algunos momentos recuerda al Joseph K. de Franz Kafka; no se olvide que Josep $\mathrm{K}$ asume una culpa desconocida, "culpa sin delito", y el señor Cantor asume con un coste terrible para su persona una culpa de la que no es responsable, tan solo es una víctima más. Tanto Josep $\mathrm{K}$ como el señor Cantor viven sus respectivas pesadillas: uno, la pesadilla de tener que defenderse de no se sabe qué y el otro de la pesadilla de la polio en Newark e Indian Hill. El caso es que ambos acaban cargando con la culpa, injustamente. Philip Roth apuesta por lo más difícil porque la novela, mezcla sin duda de ficción y de realidad, expone sin resentirse datos numéricos de enfermos y muertos, la evolución del cuadro clínico (fiebre, espasmos musculares, parálisis, etc.), el pánico que producía el pulmón de acero o la terapia de la enfermera australiana Elizabeth Kenny (1886-1952). Es sabido que la Hermana Kenny utilizaba el tratamiento con calor húmedo en la fase aguda de la enfermedad para combatir los espasmos musculares; posteriormente, una vez pasada la fase de dolor, realizaba la movilización pasiva de los músculos; en definitiva: rehabilitar en vez de inmovilizar (figuras 2 y 3). Philip Roth describe magistralmente los padecimientos de Bucky Cantor, desde los primeros síntomas a la terapia de la Hermana Kenny, no en vano la enfermera australiana recorrió los Estados Unidos y Canadá en los años 40 para explicar su método a las enfermeras; aunque sea larga la cita, merece la pena leerla con atención:

"Y finalmente empezó el cataclismo: el monstruoso dolor de cabeza, el agotamiento 
debilitante, las fuertes náuseas, la fiebre muy alta, el insoportable dolor muscular, seguidos al cabo de otras cuarenta y ocho horas por la parálisis. Permaneció ingresado tres semanas antes de que dejara de necesitar catéteres y enemas, y lo trasladaron a la planta superior para iniciar el tratamiento con compresas de lana calientes que le aplicaban alrededor de brazos y piernas, pues tenía las cuatro extremidades dañadas. Sufría cuatro penosas sesiones con las compresas calientes, que en conjunto duraban de cuatro a seis horas todos los días. Por suerte la enfermedad no le había afectado a los músculos respiratorios, por lo que no fue necesario introducirlo en un pulmón de acero que le ayudara a respirar (...). Finalmente (lo) trasladaron en ambulancia al Instituto Hermana Kenny de Filadelfia (...). Allí continuó el tratamiento por medio de compresas calientes, junto con dolorosos estiramientos de los músculos contraídos de los brazos, las piernas y la espalda...".

Merece la pena, con fines didácticos, insistir con una descripción más pormenorizada de la terapia de Elizabeth Kenny (Glanzmann, 1946). Leamos:

"La resolución de estos espasmos musculares durante el primer tiempo del período paralítico representa la primera y principal intención del tratamiento

Kenny. El espasmo muscular puede ser fácilmente localizado por el médico ante la presencia de dolores en el músculo correspondiente y por la limitación de sus movimientos activos y pasivos (...). El tratamiento precisa iniciarlo inmediatamente. Consiste en mojar un trapo de franela en agua caliente, escurriéndolo dos veces, al lado mismo de la cama del enfermo, y aplicándolo rápidamente en el miembro. La compresa debe cubrir totalmente la región del músculo espástico sin que impida los movimientos de las articulaciones. Esta compresa húmeda y caliente se cubre con una tela impermeable y luego con un paño de franela seco. Se cambiará cada dos horas, y en algunos casos cada cuarto de hora,

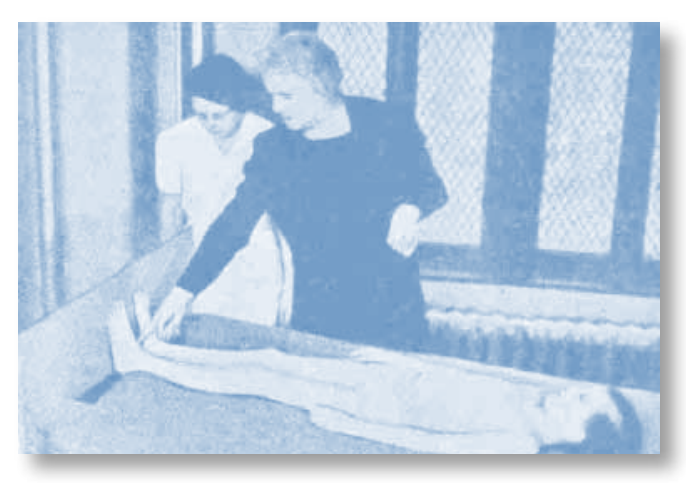

Figura 2: Método de Miss Kenny. Apoyo para evitar el pie equino (Fotografía tomada de Glanzmann, 1946).

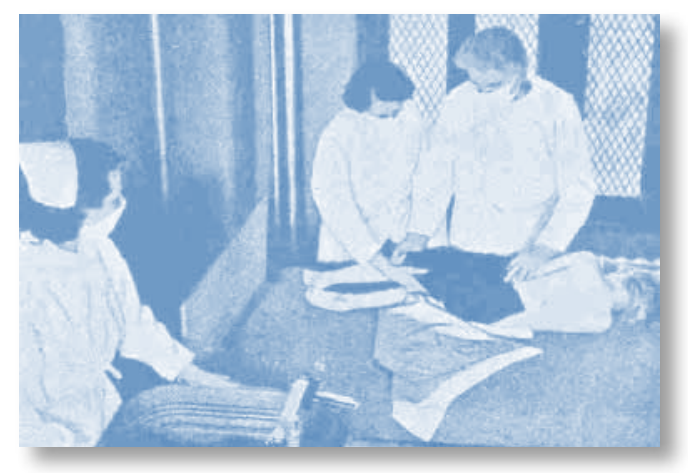

Figura 3: Método de Miss Kenny para el tratamiento de la parálisis infantil (Fotografía tomada de Glanzmann, 1946, que a su vez la tomó de JAMA, volumen 118, número 17, 1942). durante las doce horas del día. No se emplean pomadas. Hay que evitar las quemaduras escurriendo la compresa hasta que quede bien seca. Con este tratamiento desaparecen los espasmos regularmente al cabo de una semana. El tratamiento debe proseguirse hasta que el músculo contraído se relaje y sean posibles los movimientos articulares normales (...). Mis Kenny rechaza, $y$ con razón, el antiguo tratamiento que inmovilizaba a los miembros con vendajes de fijación (...). De todos modos, precisa evitar que durante el tratamiento precoz según el método de Kenny se incurra en 
practicar ejercicios y masajes demasiados violentos que pueden ser perjudiciales y empeorar la parálisis".

Se debe subrayar que el método de Miss Kenny tuvo detractores en 1944, lo comprobamos en el siguiente texto de Barraquer y Sales: "Mucho se ha hablado en estos últimos tiempos del método de Miss Kenny, (...). Estas maniobras no pueden perjudicar al enfermo e incluso son favorables; pero sin duda todo ello ha sido excesivamente sobrevalorado. Una Comisión Americana (1944) nombrada para estudiar $y$ evaluar el método de Kenny llegó a la conclusión de que <no previene ni siquiera disminuye el grado de parálisis permanente $>$ ". Sin embargo Farreras y Rozman, en la década de los setenta, recomiendan "los fomentos calientes húmedos (4 sesiones al día de 1 hora) sobre los músculos doloridos y espasmodizados".

Philip Roth, pues, describe el calvario clínico y terapéutico del señor Cantor, pero sobre todo su hipertrofiado sentimiento de culpa que le hace vivir la enfermedad como un castigo que debilita su identidad y acentúa su vulnerabilidad, convirtiéndose en una sombra que no vive sino que sobrevive, prisionero para siempre de todo lo que sucedió en 1944. Al leer la novela se aprecia que Bucky Cantor, en 1971, décadas después de la epidemia, padece también lo que se llama el síndrome postpolio. Leamos este párrafo para comprobarlo:

"El señor Cantor aún tenía el brazo izquierdo imposibilitado y la mano izquierda inútil, y renqueaba a causa de las lesiones en la musculatura de la pantorrilla izquierda. La pierna había empezado a debilitársele mucho en los últimos años, tanto en la parte inferior como en la superior, y también había empezado a dolerle intensamente por primera vez desde su rehabilitación casi treinta años atrás. En consecuencia, tras los exámenes médicos y un par de visitas a la tienda de material ortopédico de su hospital, había empezado a ponerse debajo del pantalón una abrazadera que le sujetaba la pierna izquierda. Apenas le aliviaba el dolor, pero junto con un bastón le ayudaba a mantener el equilibrio y la estabilidad en los pies. No obstante, el mismo señor Cantor decía que si continuaba empeorando-como les sucede a menudo al cabo de los años a muchos supervivientes de la polio que padecen lo que se conoce como síndrome pospoliomielítico-, más tarde o más temprano acabaría en una silla de ruedas".

José María Guelbenzu lo ha expresado bien: “...Némesis se parece más a una tragedia en la medida que el destino implacable actúa sobre el personaje". Bien señalado porque la tragedia, el destino y la culpa comienzan a tejer su tupida red sobre el señor Cantor desde la muerte de su madre en el parto. En definitiva podemos concluir que en "Némesis" la epidemia, el miedo y la culpa ofrecen un retablo de las obsesiones y temores del pueblo norteamericano, como bien ha expresado Rosa Ballester al estudiar la obra de David M. Oshinsky. Obsesiones y temores que son colectivos, pero que obran y, sobre todo dañan, a personas concretas en esta terrible década de los cuarenta; década, como hemos visto, marcada por la guerra y la enfermedad.

\section{AGRADECIMIENTOS}

- A Miguel Ángel Ruiz Jiménez que me recomendó esta novela de Philip Roth.

- A Mari Carmen Fedriani Garci por sus traducciones del inglés.

\section{BIBLIOGRAFÍA}

- Águila Maturana, AM.; Álvarez Badillo, A.; Miangolarra Page, JC; Rodríguez Rodríguez, LP. (2002): "Influencia de las epidemias de poliomielitis sobre la rehabilitación en España (1949-1969)”. Rehabilitación (Madr): 36(1), 
pp. 42-49.

- Aguilar, A. (2011): “A golpes de martillo”. Babelia, 23 de abril.

- Aparicio Maydeu, J. (2008): “El 'strip-tease’ literario de Philip Roth. Babelia, 1 de noviembre.

- Ballester Añón, R. (2008): "Entre la metáfora y la realidad. Discapacidad e identidad en la historia de la poliomielitis". Dynamis: 28, pp. 419-425.

- Barraquer Ferré, L. y Sales Vázquez, R (1956): “Poliomielitis”. En: VALERO-RIBAS, J. (dir.): Enciclopedia Salvat de Ciencias Médicas. Salvat editores, SA. Barcelona, tomo IV, pp. 535-543.

- Caballero Bonald, JM. (1999): “Prólogo” a Camus, A.: La peste. Traducción de Rosa Chacel. Millenium. Madrid.

- Caligaris, H.: "Las huellas de un escritor excepcional". En: http://letras-uruguay.espaciolatino.como/aaa/caligaris_hugo/philip_roth_las_huellas.htm (Consultado el 17 de septiembre de 2011).

- Camus, A. (1999): La peste. Traducción de Rosa Chacel y prólogo de José Manuel Caballero Bonald. Millenium. Madrid.

- Ceballos, C., A (1944): "Breves observaciones sobre la poliomielitis y su tratamiento". Boletín de la Oficina Sanitaria Panamericana: 23(12), pp. 1.072-1.080.

- Christie, A. (2003): Némesis. Debolsillo. Barcelona.

- Cruz Hernández, M. (1972): Pediatría y Puericultura. Editorial Romargraf. Barcelona, tomo 2º, pp. 1553-1576.

- Farreras Valentí, P. y Rozman, C. (1978): Medicina Interna. Editorial Marín, SA. Barcelona, tomo II, pp. 815 y ss.

- Glanzmann, E. (1946): La parálisis infantil epidémica (poliomielitis). Versión española y notas de Pedro Farreras Valentí y Agustín Pérez Soler. Colección Española de Monografías Médicas. Barcelona.

- González Rodríguez, P. (1953): Aspectos epidemiológico y social de la poliomielitis. La parálisis infantil en España. Madrid.

- Guelbenzu, JM. (2011): "La culpa y el destino". Babelia, 12 de marzo.

- Herrera Rodríguez, F. (2006): Antonio Orozco Acuaviva: un médico humanista en la Academia Hispanoamericana. Real Academia Hispanoamericana. Cádiz.

- Herrera Rodríguez, F. (2011): Las enfermedades de Sísi- fo. Reflexiones sobre literatura, medicina y enfermedad. Imprenta Rimada. Cádiz.

- Kafka, F (1984): El proceso. Traducción de Feliu Formosa. Editorial Bruguera. Barcelona, 1984.

- Laval R., E. (2007): “Anotaciones para la historia de la poliomielitis en Chile”. Rev. Chil. Infect: 24(3), pp. 247-250.

- Lax, E.: “Conversaciones con Woody Allen”. En: http:// www.casadellibro.com/capitulos/9788426436759.pdf (Consultado el 17 de septiembre de 2011).

- León Rega, P. y Echevarria Mayo, JM: "La poliomielitis y el síndrome post-polio: una breve revisión". En: http:// www.postpoliomexico.org/PolioPostPolioBreveResumen.html (Consultado el 14 de julio de 2011).

- Márquez, AC.: “Faulkner's presence in latin American literatura". En: http://dspace.uah.es/jspui/bistream/10017/4820/1/Faulkner's\%20Presence\%20in\%20 Latin\%20American\%20Literature.pdf (Consultado el 3 de agosto de 2011).

- Nájera, E. y col. (1975): “Análisis epidemiológico de la situación actual de la poliomielitis en España”. Revista de Sanidad e Higiene Pública: 49, pp. 953 y ss.

- Nettel, G.: “El pecho, de Phillip Roth”. En: http://letraslibres.com/resvista/libros/el-pecho-de-phillip-roth (Consultado el 17 de septiembre de 2011).

- Nueva Enciclopedia Larousse (1984). Barcelona, tomo 7, p. 6943.

- Núñez, S.: "Epidemia de poliomielitis en Costa Rica. Año 1944". En: http://hist.library.paho.org/Spanish/BOL/ v24n8p681.pdf (Consultado el 14 de julio de 2011).

- Núñez, S. (1945): “Poliomielitis. Epidemia en Costa Rica, año 1944”. Revista Médica de Costa Rica: XII, 136, pp. 497-500.

- Pérez Marc, G. (2007): "Filosofía de la enfermedad: vulnerabilidad del sujeto enfermo". Archivo Argentino de Pediatría: 105(2), pp. 134-142.

- Platero, S.: "Un judío incómodo". Diario El País (Montevideo, Uruguay), 1-X-2010. En: http://www.elpais. com.uy/suplemento/cultural/un-judio-incomodo/cultural_518092_1... (Consultado el 14 de agosto de 2011).

- Righetti, M. (2006): "Historias de vida entre la literatura y la ciencia”. Perfiles educativos: XXVIII (2006), 113, pp. 81-105. 


\section{ᄃultura de las Cuidados}

- Roth, Philip (2002): El animal moribundo. Traducción de Jordi Fibla. Alfaguara. Madrid.

- Roth, Philip (2006): El pecho. Traducción de Jordi Fibla. Mondadori. Barcelona.

- Roth, Philip (2007): Patrimonio. Una historia verdadera. Traducción de Ramón Buenaventura. Debolsillo. Barcelona.

- Roth, Philip (2009): Los hechos. Traducción de Ramón Buenaventura. Debolsillo. Barcelona.

- Roth, Philip (2010): Lectura de mí mismo. Traducción de Jordi Fibla. Debolsillo. Barcelona.

- Roth, Philip (2011): Némesis. Traducción de Jordi Fibla. Mondadori. Barcelona.

- Ryken, A.: "Polio in Twentieh Century America: A "Children's Disease" in a Child-Centered Culture. En: http://digitalcommons.lmu.edu/cgi/ viewcontent.cgi ?article $=1024 \&$ context $=$ ulra\&sei- -redir $=1$ \# search=\%22PARALYZING\%20FEAR\%20 NINA\%20GOLDEN\%22 (Consultado el 1 de septiembre de 2011).

- Sarabia, B. (1985): "Historias de Vida”. Revista Española de Investigaciones Sociológicas: 29, pp. 165-186.

- Soiza Larrosa, A. (2005): “La peste”. Salud Militar: 27, 1, pp. 113-126.

- Twain, M. (2007): Reflexiones contra la religión. Traducción de Mario Muchnik. Trama editorial. Madrid.

- Vargas Llosa, M. (2007): La verdad de las mentiras. Punto de Lectura. Madrid, 2007.

- Verdú, V. (2011): “Los enfermos hablan entre sî". El País, 2 de julio, p. 34.

- Wilson, Daniel J. (2009): "And they shall walk: ideal versus reality in polio rehabilitation in the United States". Asclepio: LXI, 1, pp. 175-192.

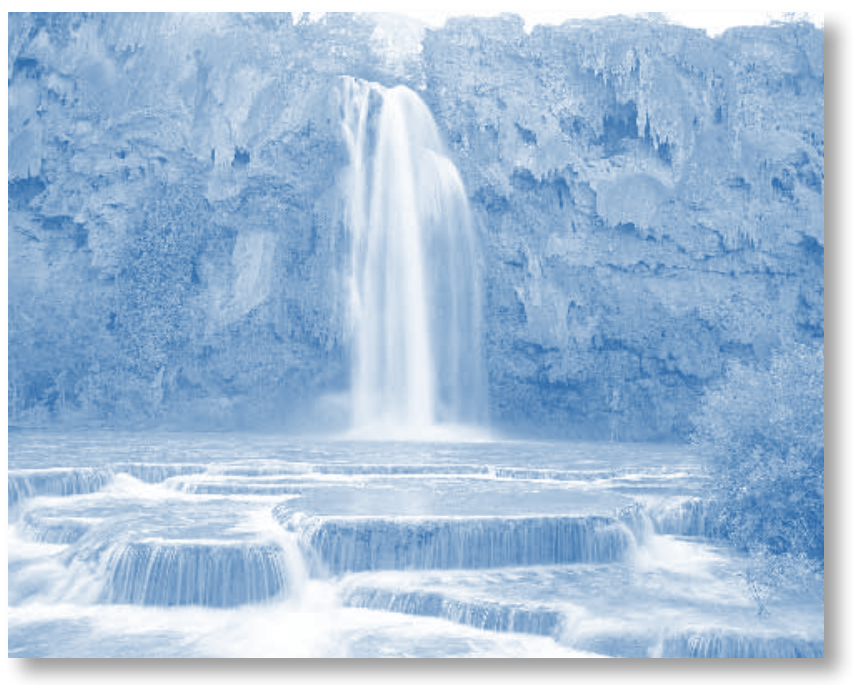

